Acta Protozool. (2019) 58: 1-5

www.ejournals.eu/Acta-Protozoologica doi:10.4467/16890027AP.19.001.10832

\title{
First Molecular Detection of Giardia duodenalis Assemblage B in a Free- Living European Wildcat (Felis s. silvestris) from Luxembourg
}

\author{
Piotr SOLARCZYK ${ }^{1}$, Natalia OSTEN-SACKEN ${ }^{2,3}$ Alain C. FRANTZ ${ }^{4}$, Simone SCHNEIDER ${ }^{4,5}$, \\ Jacques B. PIR ${ }^{4}$, Mike HEDDERGOTT ${ }^{4}$ \\ ${ }^{1}$ Department of Biology and Medical Parasitology, Poznan University of Medical Science, Poznan, Poland \\ ${ }^{2}$ Centre for Veterinary Sciences, Nicolaus Copernicus University, Toruń, Poland \\ ${ }^{3}$ Fondation Fauna-Flora, Luxembourg \\ ${ }^{4}$ Musée National d'Histoire Naturelle, 2160 Luxembourg \\ ${ }^{5}$ Biological Station SICONA, OIm, Luxembourg
}

\begin{abstract}
Giardia duodenalis is one of the most widespread intestinal parasites of humans and other vertebrates. In terms of public health, identification of Giardia assemblages in wildlife is important because only some assemblages of G. duodenalis can infect humans. Here, we use loop-mediated isothermal amplification (LAMP) and genotyping of analysis of the $\beta$-giardin gene to screen the zoonotic assemblages of G. duodenalis recovered from faeces of free-living European wildcats (Felis s. silvestris) from Luxembourg. Giardia DNA was detected in one animal (10\%) and assigned to assemblage B by both methods. This is the first detection and genotyping of G. duodenalis in a European wild felid in general, and of assemblage B in particular. Free-living wildcats may act as reservoirs of G. duodenalis infectious for humans and other wildlife and domestic animals. Using a combination of LAMP- and genotyping-based methods allowed effective, sensitive, and rapid detection of a zoonotic $G$. duodenalis assemblage B in wildlife.
\end{abstract}

Key words: Giardia, molecular diagnosis, LAMP, PCR, epidemiology, zoonosis.

\section{INTRODUCTION}

The unicellular flagellate Giardia duodenalis (syns. G. intestinalis, G. lamblia) is one of the most widespread intestinal parasites of humans and many other vertebrate species (Cacciò et al. 2018). In terms of public health, identification of Giardia assemblages in

\footnotetext{
Address for correspondence: Piotr Solarczyk, Department of Biology and Medical Parasitology, Poznan University of Medical Science, 10 Fredry Street, 61-701 Poznan, Poland; E-mail: psolar@ ump.edu.pl orcid.org/0000-0002-2862-4742
}

wildlife is very important because only some assemblages or even sub-assemblages of $G$. duodenalis are capable of infecting humans (Feng and Xiao 2011). Giardia is one of the most common enteric protozoa with great environmental contamination abilities because is transmitted by excreted feaces of infected host. Transmission of the parasite may be favoured by wild species that spread the Giardia in the nature. Deposited cysts may be directly or indirectly via contaminated water ingested by other hosts belonging to wild and domestic animals or humans. However, some aspects of Giardia spillover between groups of a potential host 
species remains still unclear. Free ranging protozoanwildlife hosts including wild cats, may play a role with zoonotic transmission and public health threat. In spite of $G$. duodenalis cosmopolitan distribution it is difficult to make inferences in the role of animals as a source of human infection. Felidae may be infected by different $G$. duodenalis assemblages belonging to both zoonotic assemblages A (sub-assemblages AI, AII) and B or host-adapted assemblages D (dog specific), F (cat specific) and also sub-assemblages AIII associated with wild ruminants. Most of the previous data concerning G. duodenalis identification in felids derived from research on domestic or stray cats (Felis catus) (Cacciò et al. 2008, Cacciò et al. 2010; de Lucio et al., 2017; Gil et al., 2017; Kváč et al. 2017; Li et al. 2017; Lebbad et al. 2010; Suzuki et al. 2011; Read et al. 2004; Pallant et al. 2015; Palmer et al. 2008; Jaros et al. 2011; McDowall et al. 2011; Sotiriadou et al. 2013; Souza et al. 2007). In addition to reports from individual captive wildcats (Beck et al. 2011, Li et al. 2017, Liu et al. 2017), only one study has used molecular-based techniques and sequence analysis to identify $G$. duodenalis assemblages in feacal material from free-living wild felids (Oates et al. 2012). Given the lack of molecular genotyping of Giardia isolates from European wildcats (Felis $s$. silvestris), the aims of the present study were $(i)$ to use loop-mediated isothermal amplification (LAMP) for rapid detection of $G$. duodenalis zoonotic assemblages, (ii) and to genotype Giardia isolates recovered from wild wildcats by polymerase chain reaction (PCR).

\section{MATERIAL AND METHODS}

\section{Sampling}

Between 2008 and 2013, ten road-killed wildcats were collected in Luxembourg and stored at $-20^{\circ} \mathrm{C}$. We collected carcasses from: Mamer (49 $\left.38^{\prime} \mathrm{N} / 6^{\circ} 1^{\prime} \mathrm{E}\right)$; Garnich (49 $\left.37^{\prime} \mathrm{N} / 5^{\circ} 57^{\prime} \mathrm{E}\right)$; Rombach $\left(49^{\circ} 50^{\prime} \mathrm{N} / 5^{\circ} 45^{\prime} \mathrm{E}\right)$; Bous $\left(49^{\circ} 33^{\prime} \mathrm{N} / 6^{\circ} 20^{\prime} \mathrm{E}\right)$; Hoscheid $\left(49^{\circ} 57^{\prime} \mathrm{N} / 6^{\circ} 5^{\prime} \mathrm{E}\right) ; \quad$ Angelsberg $\left(49^{\circ} 45^{\prime} \mathrm{N} / 6^{\circ} 10^{\prime} \mathrm{E}\right) ; \quad$ Koedange (49 $\left.44^{\prime} \mathrm{N} / 6^{\circ} 13^{\prime} \mathrm{E}\right)$; Rippweiler $\quad\left(49^{\circ} 45^{\prime} \mathrm{N} / 5^{\circ} 57^{\prime} \mathrm{E}\right)$; Kopstal $\left(49^{\circ} 40^{\prime} \mathrm{N} / 6^{\circ} 4^{\prime} \mathrm{E}\right)$; Buderscheid (49 $\left.56^{\prime} \mathrm{N} / 5^{\circ} 56^{\prime} \mathrm{E}\right)$. During dissection, we collected tissue samples for genetic analysis and 30-50 g fecal samples from the large intestine. The fecal samples were placed in a plastic container containing $2.5 \%$ potassium dichromate solution and stored at $4{ }^{\circ} \mathrm{C}$ until further analysis. The age of the wildcats was determined by the Ansorge (1995) method using incremental growth lines in the enamel of a lower-jaw canine. After demineralization with $5 \%$ nitric acid $\left(\mathrm{HNO}_{3}\right)$, the teeth were cross-sectioned (width, $5 \mu \mathrm{m}$ ) with a rotary microtome (RM
2050, Leica Biosystems Nussloch GmbH, Germany) and stained with hematoxylineosin. The growth lines were counted under a B1-220A light microscope (Motic, Wetzlar, Germany) at $\times 40-100$ magnification. Following Piechocki and Stiefel (1988), animals were either classified as subadults ( $\leq 24$ months; one growth line) or adults ( $\geq 25$ months; two or more growth lines). The dataset consisted of 5 adults and 5 subadults (comprising 6 males and 4 females). The genetic investigations of the wildcats were carried out at the Senckenberg Research Institute (Gelnhausen, Germany) and showed that all animals are pure wildcats (Steyer et al. 2016).

\section{Microscopy}

Each faecal specimen was examined as a wet mount. Each sample was concentrated using the $0.85 \mathrm{M}$ sucrose gradient centrifugation technique, with the final sediment being examined using a light microscope (Axioskop, Zeiss, Germany). In order to demonstrate Giardia stages, the entire coverslip area of wet mounts was microscopically screened under high power (total magnification of x600).

\section{DNA extraction}

From each sample, total genomic DNA was directly extracted using the QIAamp ${ }^{\circledR}$ DNA Stool Mini Kit (Qiagen GmbH, Hilden, Germany) according to the manufacturer's instructions, except for an overnight incubation with Proteinase $K$. DNA was eluted in $50 \mu 1$ of elution buffer and stored at $-20{ }^{\circ} \mathrm{C}$ until LAMP and PCR assays.

\section{LAMP, PCR, sequencing and phylogeny}

The Giardia LAMP assay was designed based on a set of primers specific to the EF1- $\alpha$ gene of G. duodenalis described by Plutzer and Karanis (2009). Six complementary primers of 40 pmol each were used: F3, forward outer primer; B3, backward outer primer; FIP-forward inner primer; BIP-backward inner primer; LoopF (LF), forward loop primer; LoopB (LB), backward loop primer. LAMP reactions were conducted in $13 \mu \mathrm{l}$ of reaction mixtures: $7.5 \mu \mathrm{l}$ of 1x Isothermal Master-mix Fluorescence Dye (OptiGene Ltd., UK), $3.5 \mu \mathrm{l}$ of Primers Mix, $1 \mu \mathrm{l}$ of $\mathrm{ddH}_{2} \mathrm{O}$ and $1 \mu \mathrm{l}$ of DNA template. The reaction mixtures were incubated at $63^{\circ} \mathrm{C}$ for $60 \mathrm{~min}$ with fluorescence recording/detection every $45 \mathrm{sec}$ and subsequently, to melt the reaction products, heated to $95^{\circ} \mathrm{C}$ for $15 \mathrm{sec}$, with fluorescence recorded after every temperature change of $0.5^{\circ} \mathrm{C}$. The LAMP products were detected with the Line Gene-K Fluorescent Quantitative Detection System (Hangzou Bioer Technology Co. Ltd.). LAMP results were directly analyzed by viewing of the amplification melting curves and the threshold cycle.

We amplified a 753-base pair fragment of the $\beta$-giardin gene (bg) using $0.6 \mu \mathrm{M}$ of the $\mathrm{G} 7$ forward primer and the G759 reverse primer, as previously described (Cacciò et al. 2002). PCRs were performed in a total volume of $20 \mu \mathrm{l}$ including $10 \mu \mathrm{l}$ of AmpliTaq Gold Fast PCR Master Mix UP, $1 \mu \mathrm{l}$ of $0.6 \mu \mathrm{M}$ of primer final concentration, $5 \mu \mathrm{l}$ of DNA template and $3 \mu \mathrm{l}$ of $\mathrm{ddH}_{2} \mathrm{O}$. Amplified DNA and 100 bp DNA Ladder (Novazym, Poland) were separated on a $2 \%$ agarose gel in TAE buffer ( $2 \mathrm{M}$ Tris, $0.05 \mathrm{M}$ EDTA, $5.7 \%$ glacial acetic acid) for $90 \mathrm{~min}$ at $50 \mathrm{~V}$, stained with ethidium bromide $(0.5 \mu \mathrm{g} / \mathrm{ml})$, and visualized under UV light. All PCR and LAMP experiments included $G$. duodenalis positive controls (total genomic DNA extracted from axenically cultured trophozoites of the human isolate HP-124) and negative controls (water template) to exclude contamination of the PCR components. The PCR prod- 
uct was sequenced in both directions with the same set of primers. Sequencing was performed with BigDye Terminator v3.1 on an ABI Prism 3130XL Analyzer (Applied Biosystems, USA). Sanger sequencing trace files were checked and edited using MEGA software v.7.0 (Kumar et al. 2016). Contigs were manually aligned and assembled in GeneDoc v. 2.7.000 (Nicholas and Nicholas, 1997). Sequences were clustered using the neighbor-joining algorithm in program MEGA version 7.0, based on the Kimura 2-parameter substitution model. Bootstrap values were calculated by performing 1,000 pseudo-replicates. The nucleotide sequence of the obtained bg gene fragment was deposited in GenBank ${ }^{\circledR}(\mathrm{NCBI})$ under accession number KX685669.

\section{RESULTS AND DISCUSSION}

One $(10 \%)$ of the ten examined wildcats, a sub-adult female from Rippweiler (collection dates: 09.01.2012), was Giardia-positive. While no microscopy sample was positive, Giardia DNA was detected in the faecal sample both by the LAMP and PCR methods. The LAMP amplicon melting curve indicated a product melting temperature $\left(\mathrm{T}_{\mathrm{m}}\right)$ of $60.5^{\circ} \mathrm{C}\left( \pm 0.5^{\circ} \mathrm{C}\right)$. The sequence of the $b g$ marker was identical to $G$. duodenalis sequences obtained from humans isolates. In the neighbor-joining algorithm, the wildcat Giardia isolate clustered with Giardia reference sequences isolated from humans and representing assemblage B (Fig. 1).

In this study, we report the first detection of the potentially zoonotic $G$. duodenalis assemblage B in wildlife in Luxembourg. The Giardia infection rate in wildcats from Luxembourg was low. Nevertheless, we report the first record of $G$. duodenalis in a freeliving felid species and the first detection of Giardia in the wild member of the genus Felidae in Europe. A study on free-living felids which were conducted on 11 samples from bobcats (Lynx rufus) and mountain lions (Puma concolor), reported one Giardia positive mountain lion from the USA. The genotype of the G. duodenalis isolate from mountain lion clustered with assemblage E (Oates et al. 2012).

A few species of wild felids kept in zoos were found to be G. duodenalis positive. Most of the G. duodenalis isolates from chinese leopard (Panthera pardus japonensis), serval (Laptailurus serval) and lynx (Lynx lynx) were genotyped as assemblage A (sub-assemblage AI), whereas a singular Giardia isolates from a cheetah (Acinonyx jubatus) and one from a snow leopard (Panthera uncia) were characterized as assemblage D and C, respectively (Beck et al. 2011). As stated, isolates of $G$. duodenalis assemblage $\mathrm{F}$ were also identified in one chinese leopard (Panthera pardus fontanierii) $[=P . p$. japonensis], two siberian tigers (Panthera tigris altaica) and mix assemblages D/F in a leopard (Panthera sp.) in Chinese zoo (Li et al. 2017, Liu et al. 2017).

LAMP was effective and rapid for the screening of $G$. duodenalis in wildcat feacal samples. The specificity of the LAMP assay was high, because it used six specifically designed primers recognizing six loci on the elongation factor 1-alfa DNA target. In the present study, the LAMP reactions required lower amounts of DNA template than PCR. According to the literature, eight assemblages of $G$. duodenalis have been established. Only assemblages A and B have been found in a wide range of hosts, including various species of wild animals and humans (Cacciò et al. 2018). The LAMP technique was based on strongly conserved EF1- $\alpha$ markers which can be used only to identify two assemblage A and B (Plutzer and Karanis 2009). To overcome the limitation, the positive sample was subsequently assessed by PCR using the variable $\beta$-giardin marker to exclude presence of assemblage $\mathrm{F}$, which is hostspecific for cats. Sequencing data at the $b g$ molecular marker confirmed $G$. duodenalis assemblage B in the wildcat feacal sample. In conclusion, using LAMP and PCR based methods seems to be effective, sensitive, and rapid for the detection of zoonotic $G$. duodenalis assemblages in animals.

It is known that $\mathrm{A}$ and $\mathrm{B}$ assemblages of $G$. duodenlis are responsible for infections in humans globally. Moreover, both G. duodenalis assemblages may be present in the environment. In the other studies that were carried out in Luxemburg, Giardia cysts were mainly detected in environmental samples (Helmi et al. 2011; Burnet et al. 2014, Burnet et al. 2015). Unfortunately, in these long termed studies there was lack of molecular data about $G$. duodenalis genotypes probably due to the negative PCR inhibitors effects in a surface water samples. Despite the evidence of Giardia presence both in drinking and recreational water reservoirs without molecular designation and in wildlife that might contaminate water sources, implications for public health become still unresolved in the Luxembourg. According to the National Health Laboratory of Luxembourg (LNS) there were reported no more than 20 human infections per year by gastrointestinal protozoa, including Giardia and the addressed cases were no linked with water activities or consumptions (Helmi et al. 2011). Our data indicated, that wild animals spread Giardia in nature and may contaminate water bodies but there is low risk of humans infection with $G$. duodenalis by drinking or 


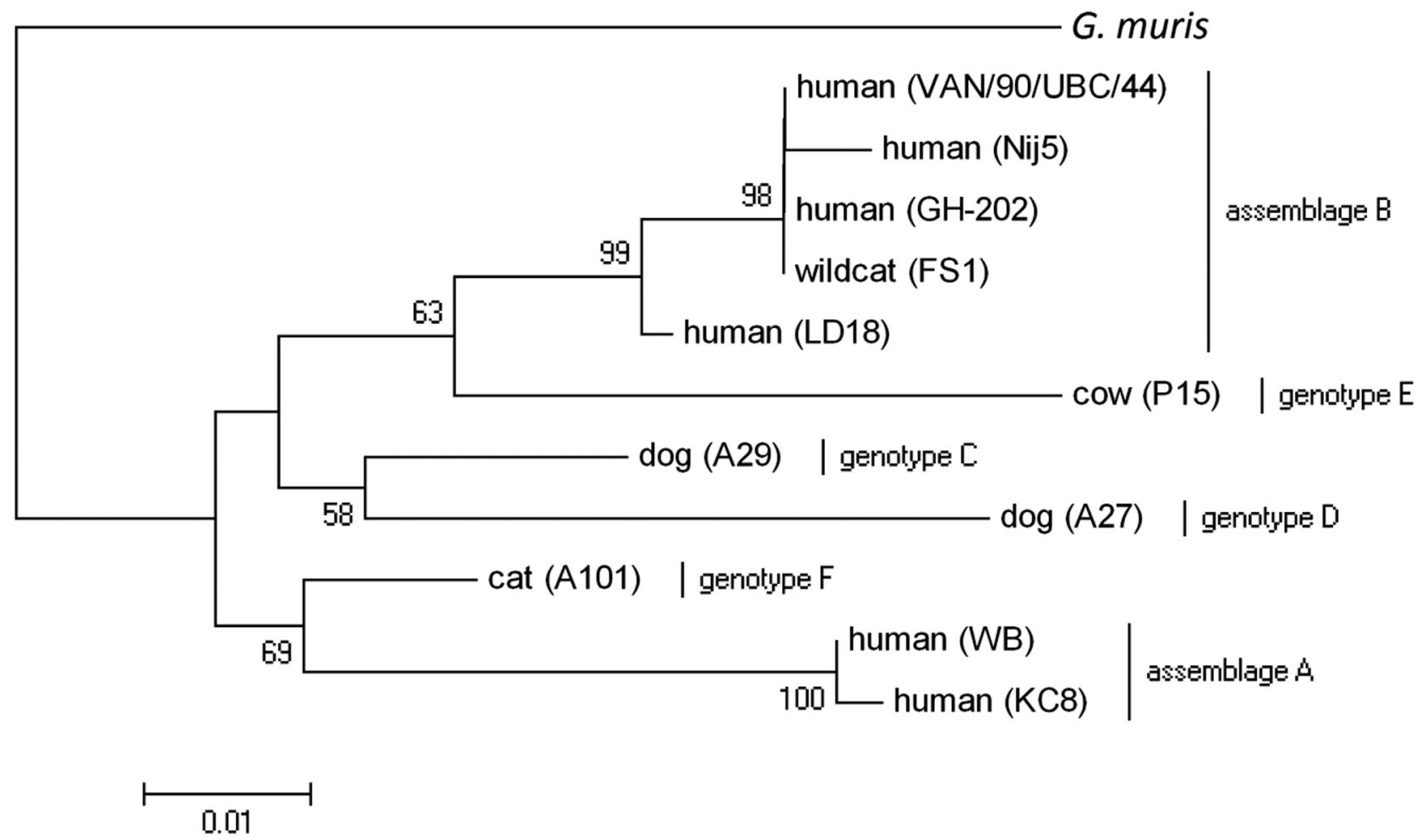

Fig. 1. Neighbor-joining distance analysis of the $\beta$-giardin nucleotide sequences. FS1 - sequence of partial $\beta$-giardin gene of the isolate from wildcat (KX685669). Reference human isolates: WB and KC8, (X85958 and AY072723); LD18, Nij5, VAN/90/UBC/44, GH202 (AY072727, AY072725, KP687755, AB618785); A101 and - cat isolate, (AY647264 and EU769206); P15 - reference cow isolate, (AY072729); A29 and A27 - reference dog isolates (AY545646 and AY545648). G. muris (AY258618) represents an outgroup.

other water activities. Wildcats shed zoonotic Giardia assemblage B and may thus be a potential source of human infection. However, environmental contamination with wildcat fecal samples that propagate the Giardia dispersive stages is probably low. Based on the low population densities and the solitary life style of wild felids, the role of wildcats in contaminating soil and surface and ground waters with the protozoa parasite is probably limited. To ultimately protect water quality and reduce indirect waterborne transmission of zoonotic G. duodenalis assemblages, it is necessary to focus on the role that free-ranging domestic cats play in spreading these potentially pathogenic protozoa. Nevertheless, it should be underlined that Giardia cross-infection among wildcats, other wildlife and domestic animals could be possible. Therefore, further studies are necessary to explain the impact of direct Giardia infection on other wild protected and/or farm animals and zoonotic transmission to human should also be elucidated.
Acknowledgements. We would like to thank G. Biver, F. Daems, L. Dondelinger, C. Felten, M. Gaston, D. Grosbusch, J. M. Guinet, S. Hermes, F. Hoss, M. Jans, J. Junck, M. Kugener, X. Mestdagh, M. Moes, G. M. Ronkaz, R. Schauls, G. Schmidt, F. Schoos, M. Schulz, F. Sowa, R. Stranen and F. Wolff for providing us with wildcat carcasses.

Funding.

The study was supported by the grant NCN Miniatura I (National Science Centre, Poland DEC-2017/01/X/NZ6/00073) and by a grant from the Luxembourg National Research Fund (AFR 7484378).

Compliance with ethical standards

Conflict of interest

The authors declare that they have no competing interests.

Ethical approval

All animals had been road-killed and were collected with the authorisation of the Luxembourg Ministry of Sustainable Development and Infrastructures (Ref.: $70646 \mathrm{GW} / \mathrm{sc}$ ). 


\section{REFERENCES}

Ansorge H. (1995) Notizen zur Altersbestimmung nach Wachstumslinien an Säugetierschädeln. In: Methoden feldökol. Säugetierforsch. Wiss Beitr Univ Halle, (Eds. M. Stubbe, A. Stubbe , D. Heidecke ) Halle, 95-102

Beck R., Sprong H., Bata I., Lucinger S., Pozio E., Cacciò S. M. (2011) Prevalence and molecular typing of Giardia spp. in captive mammals at the zoo of Zagreb, Croatia. Vet Parasitol 175(1-2): 40-46

Burnet J. B. Ogorzaly L., Penny C., Cauchie H. M. (2015) FineScale spatial heterogeneity in the distribution of waterborne protozoa in a drinking water reservoir. Int J Environ Res Public Health 12(9): 11910-1128

Burnet J. B., Penny C., Ogorzaly L., Cauchie H. M. (2014) Spatial and temporal distribution of Cryptosporidium and Giardia in a drinking water resource: implications for monitoring and risk assessment. Sci Total Environ 472: 1023-1035

Cacciò S. M., Beck R., Lalle M., Marinculic A., Pozio E. (2008) Multilocus genotyping of Giardia duodenalis reveals striking differences between assemblages $\mathrm{A}$ and $\mathrm{B}$. Int $\mathrm{J}$ Parasitol 38(13): 1523-1531

Cacciò S. M., Beck R., Almeida A., Bajer A., Pozio E. (2010) Identification of Giardia species and Giardia duodenalis assemblages by sequence analysis of the 5.8S rDNA gene and internal transcribed spacers. Parasitology 137(6): 919-925

Cacciò S. M., De Giacomo M., Pozio E. (2002) Sequence analysis of the beta-giardin gene and development of a polymerase chain reaction restriction fragment length polymorphism assay to genotype Giardia duodenalis cysts from human faecal samples. Int J Parasitol 32(8): 1023-1030

Cacciò S. M., Lalle M., Svärd S. G. (2018) Host specificity in the Giardia duodenalis species complex. Infect Gent Evol 66: 335345

de Lucio A., Bailo B., Aguilera M., Cardona G. A., Fernández-Crespo J. C., Carmena D. (2017) No molecular epidemiological evidence supporting household transmission of zoonotic Giardia duodenalis and Cryptosporidium spp. from pet dogs and cats in the province of Álava, Northern Spain. Acta Trop 170: 48-56

Helmi K., Skraber S., Burnet J. B., Leblanc L., Hoffmann L., Cauchie H. M. (2011) Two-year monitoring of Cryptosporidium parvum and Giardia lamblia occurrence in a recreational and drinking water reservoir using standard microscopic and molecular biology techniques. Environ Monit Assess 179(1-4): $163-175$

Jaros D., Zygner W., Jaros S., Wedrychowicz W. (2011) Detection of Giardia intestinalis assemblages A, B and D in domestic cats from Warsaw, Poland. Pol J Microbiol 60(3): 259-263

Feng Y., Xiao L. (2011) Zoonotic potential and molecular epidemiology of Giardia species and Giardiasis. Clin Microbiol Rev 24(1): 110-140

Gil H., Cano L., de Lucio A., Bailo B., de Mingo M. H., Cardona G. A., Fernández-Basterra J. A., Aramburu-Aguirre J., LópezMolina N., Carmena D. (2017) Detection and molecular diversity of Giardia duodenalis and Cryptosporidium spp. in sheltered dogs and cats in Northern Spain. Infect Genet Evol 50: 62-69

Li J., Wang H., Wang R., Zhang L. (2017) Giardia duodenalis infections in humans and other animals in China. Front Microbiol 8: 2004

Liu H., Shen Y., Liu A., Yin J., Yuan Z., Jiang Y., Pan W., Zhang Y., Zhao W., Cao J. (2017) Occurrence and multilocus genotyping of Giardia duodenalis in pets and zoo animals in Shanghai, China. The Journal of Infection in Developing Countries 11(6): 479-486
Kumar S., Stecher G., Tamura K. (2016) MEGA7: Molecular Evolutionary Genetics Analysis Version 7.0 for Bigger Datasets. Mol Biol Evol 33(7): 1870-1874

Kváč M., Hofmannová L., Ortega Y., Holubová N., Horčičková M., Kicia M., Hlásková L., Květoňová D., Sak B., McEvoy J. (2017) Stray cats are more frequently infected with zoonotic protists than pet cats. Folia Parasitol (Praha) 64: 034

Lebbad M., Mattsson J. G., Christensson B., Ljungström B., Backhans A., Andersson J. O., Svärd S. G. (2010) From mouse to moose: Multilocus genotyping of Giardia isolates from various animal species. Vet Parasitol 168(3-4): 231-239

McDowall R. M., Peregrine A. S., Leonard E. K., Lacombe C., Lake M., Rebelo A. R., Cai H. Y. (2011) Evaluation of the zoonotic potential of Giardia duodenalis in fecal samples from dogs and cats in Ontario. Can Vet J 52(12): 1329-1333

Oates S. C., Miller M. A., Hardin D., Conrad P. A., Melli A., Jessup D. A., Dominik C., Roug A., Tinker M.T., Miller W. A. (2012) Prevalence, environmental loading, and molecular characterization of Cryptosporidium and Giardia isolates from domestic and wild animals along the Central California Coast. Appl Environ Microbiol 78(24): 8762-8772

Palmer C. S., Traub R. J., Robertson I. D., Devlin G., Rees R., Thompson R. C. (2008) Determining the zoonotic significance of Giardia and Cryptosporidium in Australian dogs and cats. Vet Parasitol 154(1-2): 142-147

Pallant L., Barutzki D., Schaper R., Thompson R. C. A. (2015) The epidemiology of infections with Giardia species and genotypes in well cared for dogs and cats in Germany. Parasit Vectors 8: 2

Piechocki R., Stiefel A. (1988) Über die Altersstruktur der Verluste der Wildkatze (Felis s. silvestris Schreber 1777). Hercynia N F 25: 235-258

Plutzer J., Karanis P. (2009) Rapid identification of Giardia duodenalis by loop-mediated isothermal amplification (LAMP) from faecal and environmental samples and comparative findings by PCR and real-time PCR methods. Parasitol Res 104(6): 1527-1533

Read C. M., Monis P. T., Thompson R. C. (2004) Discrimination of all genotypes of Giardia duodenalis at the glutamate dehydrogenase locus using PCR-RFLP. Infect Genet Evol 4(2): 125-130

Steyer K., Kraus R. H. S., Mölich T., Anders O., Cocchiararo B., Frosch C., Geib A., Götz M., Herrmann M., Hupe K., Kohnen A., Krüger M., Müller F., Pir J. P., Reiners T. E., Roch S., Schade U., Schiefenhövel P., Siemund M., Simon O., Steeb S., Streif S., Streit B., Thein .J, Tiesmeyer A., Trinzen M., Vogel B., Nowak C. (2016) Large-scale genetic census of an elusive carnivore, the European wildcat (Felis s. silvestris). Conserv Genet 17(5): 1183-1199

Sotiriadou I., Pantchev N., Gassmann D., Karanis P. (2013) Molecular identification of Giardia and Cryptosporidium from dogs and cats. Parasite 2013:20:8

Souza S. L., Gennari S. M., Richtzenhain L. J., Pena H. F., Funada M. R., Cortez A., Gregori F., Soares R. M. (2007) Molecular identification of Giardia duodenalis isolates from humans, dogs, cats and cattle from the state of São Paulo, Brazil, by sequence analysis of fragments of glutamate dehydrogenase $(\mathrm{gdh})$ coding gene. Vet Parasitol 149(3-4): 258-264

Suzuki J., Murata R., Kobayashi .S, Sadamasu K., Kai A., Takeuchi T. (2011) Risk of human infection with Giardia duodenalis from cats in Japan and genotyping of the isolates to assess the route of infection in cats. Parasitology 138(4): 493-500

Received on $8^{\text {th }}$ April, 2019; revised on $10^{\text {th }}$ May, 2019; accepted on $19^{\text {th }}$ June, 2019 